\title{
Mathematical Modeling Research in Fashion and Textiles Supply Chains and Operational Control Systems
}

\author{
Tsan-Ming Choi, ${ }^{1}$ Xiaohang Yue, ${ }^{2}$ Chun-Hung Chiu, ${ }^{3}$ and Pui-Sze $\mathrm{Chow}^{4}$ \\ ${ }^{1}$ Institute of Textiles and Clothing, The Hong Kong Polytechnic University, Hung Hom, Kowloon, Hong Kong \\ ${ }^{2}$ Lubar School of Business, University of Wisconsin-Milwaukee, Milwaukee, WI 53201, USA \\ ${ }^{3}$ Sun Yat-Sen Business School, Sun Yat-Sen University, Guangzhou 510275, China \\ ${ }^{4}$ Institute of Textiles and Clothing, Faculty of Applied Science and Textiles, The Hong Kong Polytechnic University, \\ Hung Hom, Hong Kong
}

Correspondence should be addressed to Tsan-Ming Choi; jason.choi@polyu.edu.hk

Received 11 March 2013; Accepted 11 March 2013

Copyright (C) 2013 Tsan-Ming Choi et al. This is an open access article distributed under the Creative Commons Attribution License, which permits unrestricted use, distribution, and reproduction in any medium, provided the original work is properly cited.

The fashion and textiles industry is one of the most important industries in the world and it has rapidly developed over the past decade. With its fast development, the corresponding supply chain systems become much more complex and a lot of challenging optimization-related issues arise. These issues span over topics such as product quality control, shipping and distribution arrangements, coordination mechanism, and inventory management. This special issue is devoted to publishing the latest and significant results on mathematical modeling research related to fashion and textiles supply chains and operational control systems. This special issue is on the interface between engineering and business and features both analytical and empirical studies. This special issue features 15 technical papers and we describe each one of them concisely as follows.

In "A heuristic approach to proposal-based negotiation: with applications in fashion supply chain management," S. Costantini et al. explore a heuristic approach to proposalbased negotiation with applications in fashion supply chain management. In their proposed model, they present and assess experimentally an extended approach which allows two supply chain agents to potentially make offers that are an internal point of its negotiation space. They report that the extended approach functions well and identify the cases in which it outperforms the original approach as reported in the literature. They discuss the usefulness of the approach for supply chain management in the fashion industry, which is a field of growing importance in economy and e-commerce. They further argue that the efficient computational models such as the one that they proposed can greatly facilitate the work of human managers in fashion (both sellers and buyers) who have to negotiate every day with multiple counterparts on multiple issues.

In "Sales rebate contracts in fashion supply chains," C. H. Chiu et al. investigate the sales rebate contract, which is a commonly adopted supply chain contract in the fashion industry, with the use of real industrial data from five companies. In their analysis, they find that sales-rebates contract can help to achieve coordination in the supply chain in which both the retailer and the manufacturer are benefited. One interesting finding is that the risk levels for attaining coordination by sales rebates contract are also higher for both the retailer and the manufacturer. They hence propose that the optimal parameters of the sales-rebate contracts should be determined with a good balance between the benefit (expected profit) and the risk (variance of profit). They argue that an inappropriate setting of sales rebate could either hurt the expected profit for the retailer or the manufacturer. Finally, they show that in the presence of sales effort, higher expected profits and lower risks for the retailers and the manufacturers can be found by using sales rebates contract.

In "Quantity discount supply chain models with fashion products and uncertain yield," H. Peng and M. Zhou explore the analytical quantity discount coordination models in 
the fashion supply chain with uncertain yields and random demand. They establish a stochastic gaming model for employing quantity discount to achieve coordination and employ it to analyze how to optimally determine the quantity discount scheme. They find that their proposed quantity discount coordination scheme can increase the manufacturer's ordering quantity for the raw material, which contributes to the desirable result of achieving the best profitability level in the fashion supply chain. They also reveal that a larger uncertainty of the yields and the demand in the supply chain will significantly affect the coordination mechanism and also the resulting fashion supply chain profit.

In "A coordination of risk management for supply chains organized as virtual enterprises," F. Lu et al. investigate the risk management for fashion supply chains organized as virtual enterprises. The aim of their study is to find the proper decision mechanisms that can improve the overall performance of risk management for the whole supply chain system and its agents as a virtual enterprise (VE). In order to deal with this challenge, they develop a centralized mechanism as a base case and then derive a novel distributed decision-making (DDM) method. Moreover, the particle swarm optimization (PSO) algorithm is designed to solve the resulting optimization problem. They find that their proposed mechanism can help to achieve a win-win situation in the fashion supply chain. They argue that the strategic partnerships among the members in a fashion supply chain organized as a VE are essential for improving the fashion supply chain's performance and responsiveness.

In "Loss-averse inventory and borrowing decisions with constraints on working capital in fashion and textiles industry," L. Ma et al. observe that decision makers in real world have different decision preferences. As a result, they use the prospect theory to model the loss-averse behavior of decision makers in a fashion supply chain and study the inventory control problems with financial constraints. By using dynamic programming, they characterize the optimal inventory replenishment policy as a capital-dependent basestock policy and study how the policy parameters change with respect to the accumulated wealth and the loss-averse indicator.

In "The impact of the strategic advertising on luxury fashion brands with social influences," J. H. Zheng et al. study the optimal strategic advertising decisions on luxury fashion brands with social influences. They observe that consumers for fashion products are influenced significantly by their social needs such as the need for uniqueness and the need of conformity when making a purchase decision. In their paper, they focus on investigating the impacts of two competing social needs which separate customers into two groups who exhibit different buying behaviors. They start by considering different advertising allocation strategies with social needs and then develop the model under which a luxury fashion brand will suffer a loss when the advertising efforts to different customer groups are not up to a certain level. In order to reveal the impact of the strategic advertising on luxury fashion brands with social influences, they derive the mechanism for the fashion brands to identify the optimal strategies and decisions in pricing and advertising budget allocation.

In "Coordinating contracts for two stage supply chain with risk-averse retailer and price dependent demand," M. Xu et al. incorporate the fashion retailer's risk aversion attitude along with pricing factor into a two-stage fashion supply chain via the classic mean-variance approach. They consider a pricedependent demand in the supply chain and discuss both single contracts and combined contracts for achieving supply chain coordination. When the risk averse fashion retailer's optimal pricing-ordering decision is equal to the vertically integrated supply chain's optimal decision, the fashion supply chain is coordinated and the whole supply chain gains the maximum profit. They find that under the single contracts scenario, the coordinating revenue sharing contract and twopart tariff contract for the supply chains with risk neutral agents could still coordinate the supply chain with a risk sensitive retailer. However, a more complicated "sales rebate and penalty" contract fails to do so. When considering combined contracts, they find that the joint revenue sharing with two-part tariff contract is able to achieve supply chain coordination.

In "The impact of subsidy policy on total factor productivity: an empirical analysis for China's cotton production," Y. W. Tan et al. investigate the impact of subsidy policy on total factor productivity for China's cotton production. Their study is motivated by an important observation that since 2007, China has carried out one subsidy policy on cotton seed in high quality (simplified as "seed subsidy") in order to motivate the farmers to produce more cotton. However, Tan et al. find that the seed subsidy policy has not achieved the devising aim to increase the productivity and the output of cotton. Motivated by this important observation, Tan et al. investigate, using a theoretical mathematic model, the relationship between the subsidy policy related to arable land and the productivity. They also explore the impact of the subsidy policy on the total factors productivity (TFP) of China's cotton production using Malmquist Index. They argue that their proposed mathematical model can interpret what would happen about the TFP after the subsidy policy is implemented. Their findings also indicate that there exists a negative relationship between the subsidy policy and TFP if the subsidy is related to planting area. They argue that promoting investment in research and development of agriculture, and enhancing technical progress in agriculture may be a better way to increase the agricultural TFP than the subsidy policy.

In "Vehicle routing problem for fashion supply chains with cross-docking," Z. H. Hu et al. address the issue of how to optimize the overall traveling time, distance, and waiting time at a cross-docking center in a fashion supply chain. In their study, they formulate the optimal route selection problems from suppliers to cross-docking center and from cross-docking center to customers as the respective vehicle routing problems (VRPs). By an integration of the two independent VRP models, they identify the optimal solutions. They propose that the fashion supply chains, especially the textiles supply chains, can use the model developed in the paper to form strategies that can significantly improve 
the overall operations performance of their cross-docking centers. Furthermore, even though the VRP is NP-hard, with their proposed mixed 0/1 integer programming model, the issue under study can be solved within a reasonable time, which significantly facilitates the practical applicability of the cross-docking model.

In "A novel ensemble learning approach for corporate financial distress forecasting in fashion and textiles supply chains," G. Xie et al. explore the prediction problem of corporate financial distress related to fashion enterprises. To achieve good forecasting performance, they propose a novel forecasting model in which a logistics regression (LR) model is integrated with artificial intelligence tools, that is, support vector machine (SVM) and back-propagation neural networks (BPNN). To be specific, in their proposed forecasting framework, the forecasting results by LR are introduced into the SVM and BPNN which can help recognizing the forecasting errors in fitness by LR. Their computational results suggest that artificial intelligence tools are better than LR and the proposed novel ensemble learning approach can achieve better forecasting performance than that of the individual models. By using the proposed approach, managers in fashion and textiles companies can predict the financial state of their suppliers, manufacturers, and retailers in advance which can greatly enhance their operations.

In "Fashion brand purity and firm performance," J. Zheng et al. develop a dynamic brand dilution model based on the economics demand curves and two fashion consumer groups: targeted group (leading group) and nontargeted group (following group). They consider the situation in which fashion companies can adjust product prices to change sales volumes, according to the demand curve, and further change the composition of LG and FG that reflects the degree of brand dilution. One significant aspect of their study is that "brand purity" is used to measure brand dilution level and this concept can quantitatively illustrate the relationship between brand dilution and firm performance including revenue and profit. They derive propositions and conduct numerical studies to explain the dilution situations that many fashion brands experienced. They argue that (1) with the strong motivation to expand customer base, fashion firms tend to dilute the brands unintentionally. (2) Brand dilution can harm firm performance significantly and can be easily aggravated. (3) To increase brand purity, firms need to exclude the FG consumers and focus on its LG consumers.

In "Clarifying cutting and sewing process with due windows using an effective ant colony optimization," R. H. Huang and S. C. Yu explore the cutting and sewing process in textiles and clothing with due windows. They formulate the problem as a two-stage flexible flow shop scheduling problem with the objective of minimizing earliness, tardiness, and makespan. They develop a novel "effective ant colony optimization (EACO)" method to solve the problem. Their computational results indicate that for either small or large problems, EACO is more effective than the particle swarm optimization algorithm and the traditional ant colony optimization algorithm. They also argue that EACO can be used to solve complex flow shop scheduling problem efficiently.
In "Optimal product guality of supply chain based on information traceability in fashion and textiles industry: an adverse logistics perspective," Z. Cheng et al. investigate and compare two quality control methods, namely, the inspection control and the traceability control, to optimize supply chain quality in the fashion and textiles industry. They consider quality as a controllable variable indicating the level of opportunistic behavior. They model "return" as a function of quality in which a higher quality implies a lower return. Based on theories of resource-based view (RBV) and dynamic capability view (DCV), they propose that the product type, the manufacturer's technology capability, and the standardization level all affect the manufacturer's choice of quality control methods (inspection versus traceability). They further reveal that the manufacturer's optimal strategy of quality control is to impose appropriate punishment measures given the high cost of replacing suppliers. Taking into account both quality and inventory quantity, they propose a newsvendor model-based adverse logistics model to analyze and compare the two different methods for supply chain quality control. Furthermore, they analyze and discuss the differences in the applications and scopes of the two control methods. Through examining the model and the numerical example, they discuss the four propositions and their implications to optimal supply chain quality management in the fashion and textiles industry. With the improved industrial standardization and technology, they believe that there is much room for the manufacturer to use information technology to improve products quality in fashion and textiles industry in the future.

In "No refund or full refund: when should a fashion brand offer consumer return with full refund for mass customization products?" T. M. Choi et al. explore the mass customization problem in fashion supply chains with the consideration of consumer demand uncertainty and risk aversion of the company. Under the mean-variance framework, they study how the degree of risk aversion affects the company's decision on optimal retail pricing and modularity level. They also examine the interesting research question on when the MC companies should offer consumer return with full refund. They find that for the scenario with full refund and return, the optimal retail price and the optimal modularity level would vary monotonically with respect to the return service charge and the salvage value when some analytical conditions are satisfied. For the case when return is not allowed, they find that the optimal retail price and the optimal modularity level are decreasing in the MC company's level of risk aversion and the demand uncertainty. They also find that the optimal retail pricing decision is linearly proportional to the optimal modularity decision for both cases under study. They finally reveal that whether it is beneficial for the MC fashion company to offer consumer return with full refund (compared to no return) depends on the demand-return correlation coefficient.

In "Collective recycling responsibility in closed-loop fashion supply chains with a third party: Financial sharing or physical sharing?" J. Nie et al. study the collective recycling responsibility in closed-loop fashion supply chain systems with a third party. They examine three models where the manufacturer may either offer a financial or physical support 
(called collective recycling responsibility) for a third party to collect the used goods for remanufacturing. They reveal that if the manufacturer offers either kind of support to the third-party firm, the retail price will decrease and the demand will increase. In addition, all supply chain agents in this closed-loop supply chain will prefer the presence of the financial or the physical support. The situation under which the financial support outperforms the physical support depends on a critical factor which is "the transfer price of the used product."

We believe that this special issue presents many interesting research on fashion and textile supply chain management problems. The published papers also provide a good foundation for future research related to mathematical models for fashion and textile supply chains and operational control problems.

Tsan-Ming Choi Xiaohang Yue

Chun-Hung Chiu Pui-Sze Chow 


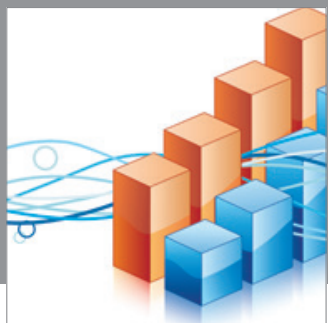

Advances in

Operations Research

mansans

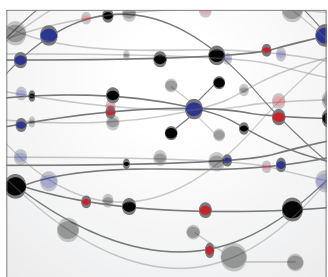

The Scientific World Journal
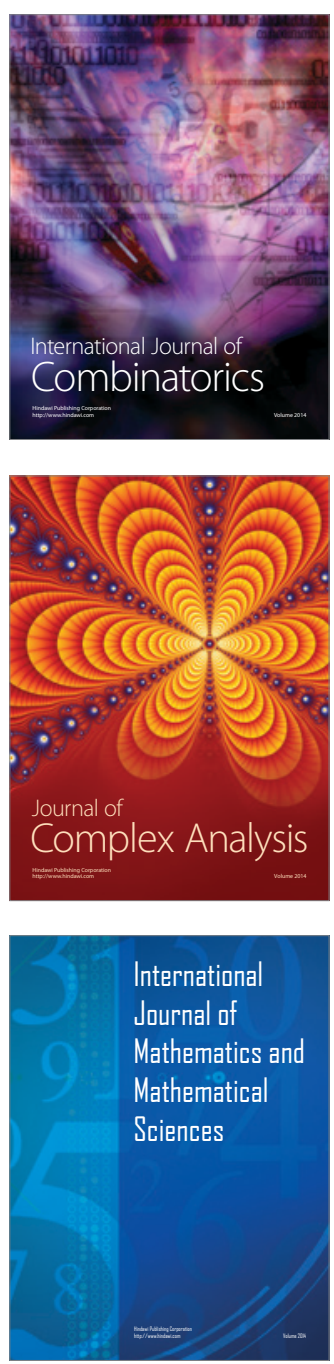
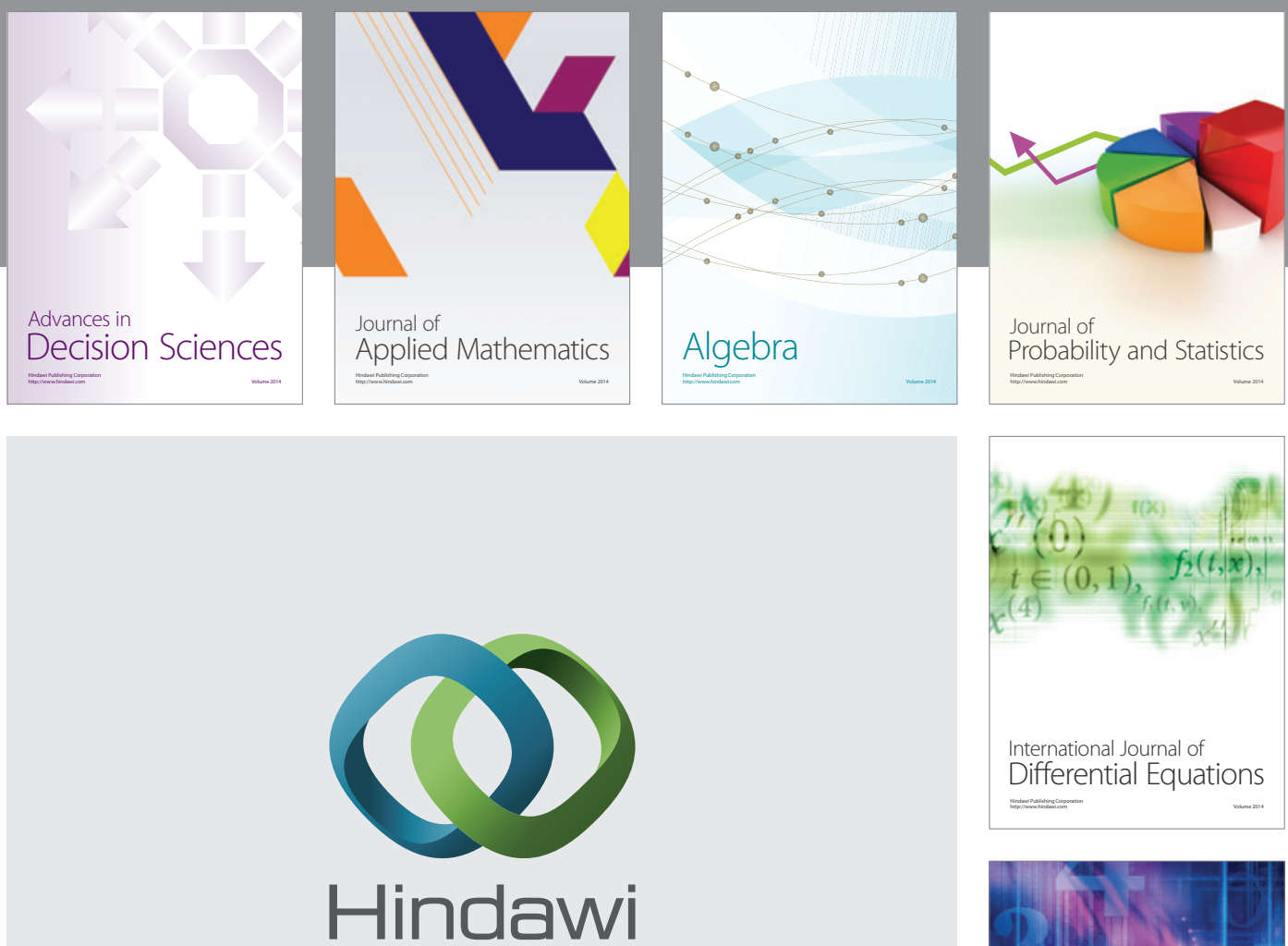

Submit your manuscripts at http://www.hindawi.com
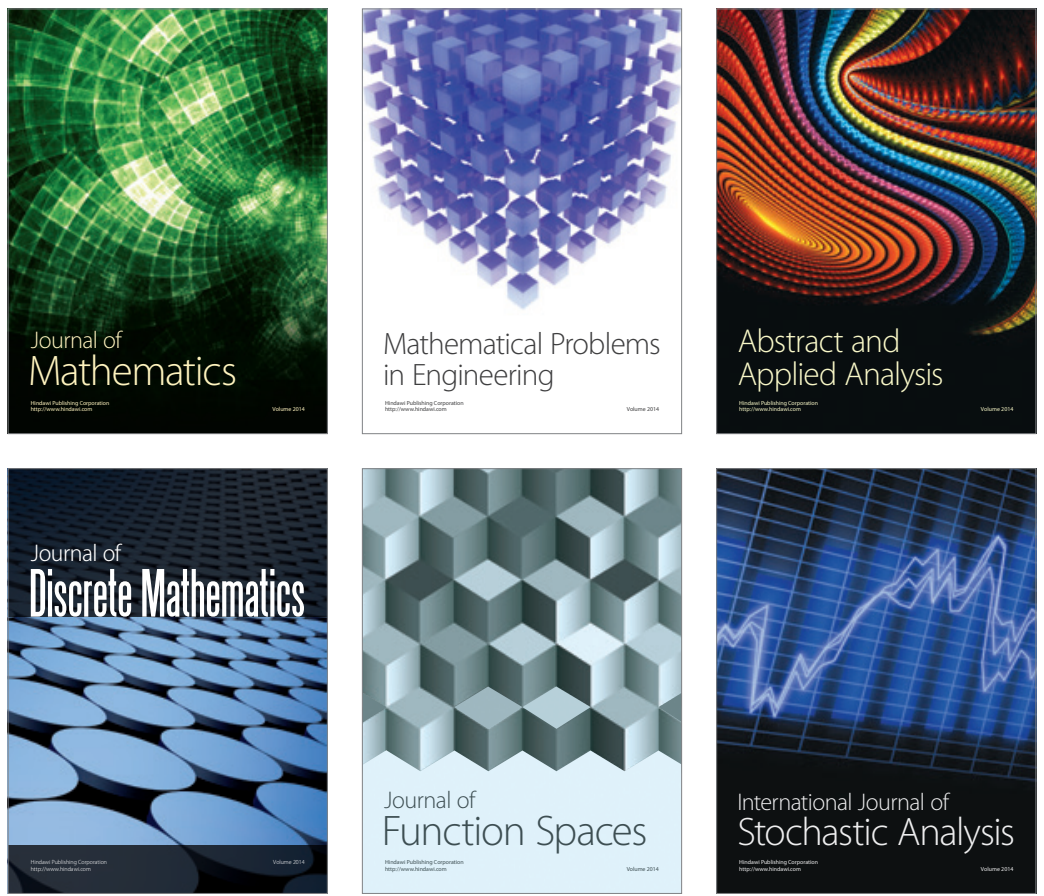

Journal of

Function Spaces

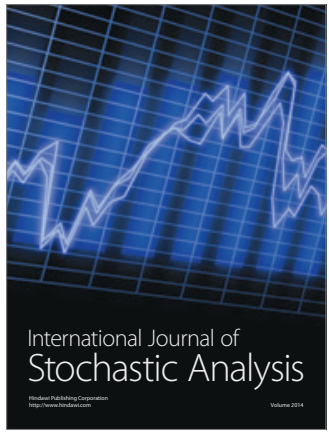

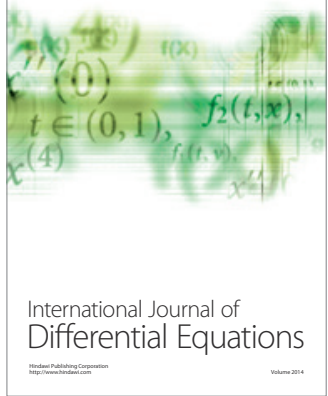
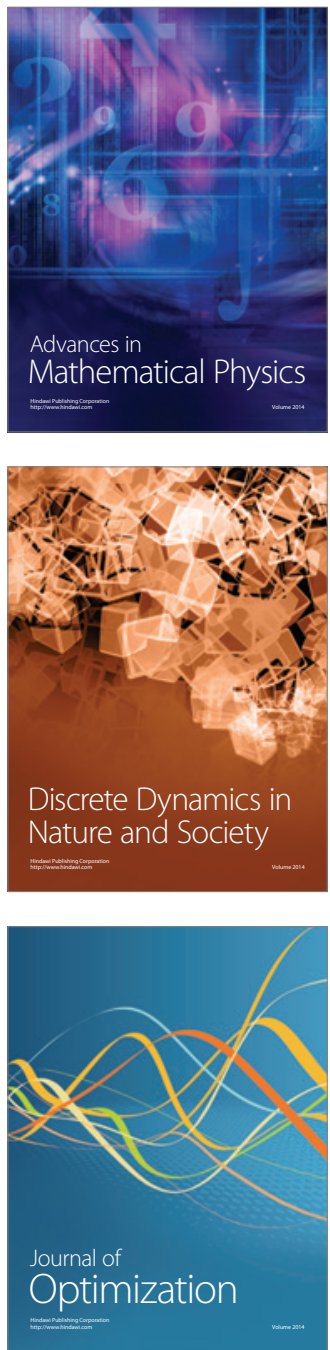